\title{
Prof. Dr. Beatriz Tavares Costa-Carvalho Obituary
}

\section{Antonio Condino-Neto ${ }^{1}$}

Received: 5 June 2019 / Accepted: 6 June 2019 / Published online: 18 June 2019

(C) Springer Science+Business Media, LLC, part of Springer Nature 2019

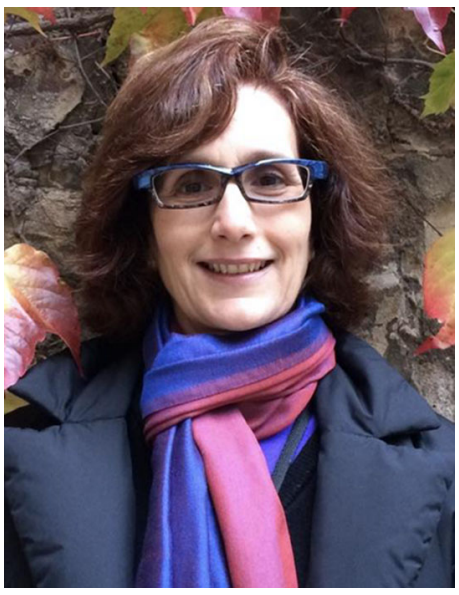

With sadness, we communicate that Dr. Beatriz CostaCarvalho passed away on May 26, 2019. She was a distinguished professor of Pediatrics and Immunology at the Federal University of São Paulo, Brazil, and founded the Brazilian Group of Primary Immunodeficiencies in 2001 (www.bragid.org.br).

Under her leadership, this group established strong connections and actively collaborated with the Brazilian Society of Pediatrics, Brazilian Society of Allergy and Immunology, and the Latin American Society of Primary Immunodeficiencies. The result was very impactful and changed the reality of primary immunodeficiencies in Brazil. Beatriz has influenced many young and senior doctors in Brazil. Her work outreached the international community. In 2007, the Jeffrey Modell Foundation started the first JMF center in Latin America under her direction. This allowed her to establish productive international collaborations that definitely made possible young Brazilian doctors and scientists to train and collaborate worldwide in the field of primary immunodeficiencies. In the last 3 years, Brazil increased the prescription of immunoglobulins in $200 \%$, clearly showing that the number of diagnosed cases is dramatically increasing in our country, a fact certainly connected with Beatriz's work.

BRAGID strongly supported the implementation of LASID Registry in 2009 (over 8000 cases throughout Latin America), three LASID PID schools in 2006 (Campinas-SP), 2010 (Bahia), and 2014 (Campinas-SP), and the newborn screening pilot program in Brazil since 2011, currently in phase 4 with over 50 SCID cases.

Beatriz has published many papers in peer-reviewed journals as well as book chapters. Her passion was clearly the care of patients and the education of doctors and her fellows. Her endless love and dedication to the cause of PID and her legacy will remain and influence forever the field of primary immunodeficiencies.

Publisher's Note Springer Nature remains neutral with regard to jurisdictional claims in published maps and institutional affiliations.

Antonio Condino-Neto

antoniocondino@gmail.com

1 Institute of Biomedical Sciences, University of São Paulo, São Paulo, SP, Brazil 